\title{
O DIREITO HUMANO À ALIMENTAÇÃO ADEQUADA: INTERDIMENSIONALIDADE, EFETIVIDADE, DESENVOLVIMENTO HUMANO E DIGNIDADE DA PESSOA HUMANA
}

\author{
Regina Vera Villas Bôas ${ }^{1}$ \\ Durcelania da Silva Soares ${ }^{2}$
}

Resumo: O presente artigo reporta-se ao direito humano à alimentação adequada, assegurado pela Constituição Federal como direito fundamental social em seu artigo $6^{\circ}$. Considerando que os direitos humanos materializam as exigências basilares referenciadas na dignidade da pessoa dos sujeitos de direitos, implica dizer que não são passíveis de transação em quaisquer circunstâncias e, ao mesmo tempo, configuram condições colocadas a toda efetivação histórica.

Palavras-chaves: Direito humano à alimentação adequada; Interdimensionalidade; Efetividade; Desenvolvimento Humano; Dignidade da pessoa humana.

\section{THE HUMAN RIGHT TO ADEQUATE FOOD: INTERDIMENSIONALITY, EFFECTIVENESS, HUMAN DEVELOPMENT AND DIGNITY OF THE HUMAN PERSON}

Abstract: This article refers to the human right to adequate food, guaranteed by the Federal Constitution as a fundamental social right in its article 6. Considering that human rights materialize the basic requirements referenced in the person's dignity of the subjects of rights, it implies that they are not subject to transaction under any circumstances and, at the same time, configure conditions placed on all historical effectiveness.

Keywords: Human right to adequate food; Interdimensionality; Effectiveness; Human development; Dignity of human person;

\section{INTRODUÇÃO}

Desde os tempos remotos a pessoa humana vive empenhada em uma luta contra a fome e a pobreza. Essa luta está inscrita na própria trajetória humana. Luta-se pelo direito

\footnotetext{
${ }^{1}$ Pós-Doutora em Democracia e Direitos Humanos pela Universidade de Coimbra - lus Gentium Conimbrigae. Bi-Doutora em Direito Privado e em Dir. Difusos e Coletivos, Mestre em Direito Rel. Sociais, e Graduada em Direito, todos pela PUC/SP. Coord. JEC da PUC/SP. Prof. e Pesq. PG e PPG da PUC/SP e do UNISAL/SP (Lorena). Coord. do PP/PUC-SP "Efetividade/F/T e Contemp DH, DF, Sociais, Difusos e Coletivos: Diálogos das Fontes, e do PP/UNISAL "D e DF: Vulner./Instrumentos de Concretização", integrando Obs. Viol. Escolas (UNESCO/UNISAL). Membro colab.última gestão da OAB/SP (Com. D. Civil e da P. Deficiência). Aval. INEPE. http://orcid.org/0000-0002-3310-4274,_CV: http://lattes.cnpq.br/4695452665454054. E-mail: revillasboas1954@gmail.com

${ }^{2}$ Mestre em Direito. Docente na Universidade Estácio de Sá - RJ. E-mail: durcelania@hotmail.com - ORCID iD https://orcid.org/0000-0001-8538-8849 - http://lattes.cnpq.br/1543810316645867
} 
humano à alimentação adequada, que tem sido brutalmente violado pelo próprio Estado garantidor, que há tempos tem se transformado em um Estado violador.

Os movimentos sociais têm lutado de forma contínua em busca da efetivação do direito humano à alimentação adequada a todos os humanos, e essa efetivação necessariamente passa pelo acesso aos alimentos.

Se a história mostra as lutas dos atores sociais pela liberdade, essa luta está atrelada às conquistas dos direitos dos homens. Os direitos humanos constituem um conjunto de faculdades e instituições que, em cada momento histórico, concretizam as exigências da dignidade, da liberdade, da igualdade humana, as quais exigem reconhecimento positivo pelos ordenamentos jurídicos, em nível nacional e internacional.

Dessa sorte a presente pesquisa, aprecia o direito humano à alimentação adequada trazendo à baila a inércia do Estado para assegurar a todos o acesso à alimentação, fato este que afeta a existência digna daqueles que não conseguem referido acesso. Observa-se que a não garantia de acesso ao DHAA - tão valioso e imprescindível à vida digna -, ao seu destinatário final, implica desrespeito aos valores da essência humana.

A presente pesquisa se vale do método investigativo bibliográfico de cunho doutrinário-legislativo, coletando dados bibliográficos para entender que a água é necessária a sobrevivência humana na Terra e que os Estados devem garantir o acesso à água de qualidade para sua população. No entanto, essa garantia nem sempre é possível quando se percebe a má gestão dos recursos hídricos.

\section{DESENVOLVIMENTO HUMANO E DIGNIDADE DA PESSOA HUMANA}

A história pela busca da efetivação dos direitos humanos sempre esteve vinculada às lutas pela liberdade construídas durante séculos pelas vítimas da opressão, sendo os direitos humanos realizados a partir de um processo histórico. "A história de todas as sociedades até hoje existentes é a história das lutas de classes". (MARX; ENGELS, 2005, p. 40). Habermas (2012, p. 11) afirma que o direito humano surge após a constatação da opressão, da humilhação, da violação da dignidade humana, que é considerada fonte moral dos direitos humanos.

A evolução dos direitos humanos originou os direitos e garantias fundamentais, "A evolução histórica dos direitos inerentes à pessoa humana também é lenta e gradual. Não são reconhecidos ou construídos todos de uma vez, mas sim conforme a própria experiência da 
vida humana em sociedade". (SIQUEIRA; PICCIRILLO, 2009, [n.p.]). A construção dos direitos humanos não está finalizada, mas continua em evolução, de forma paulatina, sendo reconhecidos aos poucos, conforme o clamor da própria sociedade na busca pelo alargamento dos direitos decorrentes das lutas libertárias. Cavalcante Filho (2017, p. 6) afirma que os direitos humanos “[...] são uma construção histórica, isto é, a concepção sobre quais são os direitos considerados fundamentais varia de época para época e de lugar para lugar".

A história das lutas pelos direitos humanos encontra-se na afirmação de Bobbio (2004, p. 5):

\begin{abstract}
Do ponto de vista teórico, sempre defendi - e continuo a defender, fortalecido por novos argumentos - que os direitos do homem, por mais fundamentais que sejam, são direitos históricos, ou seja, nascidos em certas circunstâncias, caracterizadas por lutas em defesa de novas liberdades contra velhos poderes, e nascidos de modo gradual, não todos de uma vez e nem de uma vez por todas.
\end{abstract}

Portanto, os direitos são construções históricas e surgem das lutas sociais presentes na sociedade, resultante de ações efetivadas por atores sociais históricos que, condicionados à determinantes econômicos, políticos e sociais e por configurar-se como inacabados, trazem a possibilidade de "[...] enfrentamento das mazelas produzidas pelo capitalismo". (COUTO, 2004, p. 52), visto que compõem o sistema de proteção social. Ainda complementa Celso Lafer (1988, p. 124): “[...] do século XVIII até os nossos dias, o elenco de direitos do homem contemplados nas constituições e nos instrumentos internacionais foram- se alterando com a mudança das condições históricas".

Os direitos sociais surgem, então, como conquistas dos movimentos sociais ao longo dos séculos, sendo, atualmente, reconhecidos no âmbito internacional, em documentos como a Declaração Universal dos Direitos do Homem, de 1948, o Pacto Internacional dos Direitos Econômicos, Sociais e Culturais, de 1966, e as Diretrizes Voluntárias da FAO/ONU, dentre outros.

Com o surgimento da Declaração Universal dos Direitos Humanos, nela os direitos do ser humano eram vistos como direitos inatos. Bonavides (2011, p. 578) sustenta que a Declaração Universal dos Direitos Humanos é o estatuto da liberdade de todos os povos, a Constituição das Nações Unidas, a carta magna das minorias oprimidas, o código das nacionalidades, a esperança, enfim, de promover, sem distinção de raça, sexo e religião, o respeito à dignidade do ser humano. Os direitos humanos conscientizam e declaram o que vai 
sendo adquirido nas lutas sociais e dentro da história, para transformar-se em opção jurídica indeclinável (POZZOLI; ANTICO, 2011, p. 7).

No mesmo sentido, Piovesan, Gotti e Martins (2010) sustentam que os direitos humanos refletem um construído axiológico, a partir de um espaço simbólico de luta e ação social. Trata-se de uma concepção contemporânea de direitos humanos, marcada pela universalidade e indivisibilidade desses direitos. A marca do direito humano é a luta pela liberdade e pela dignidade humana dos povos. O requisito único para a titularidade desses direitos é ser humano.

Na concepção de Pablo Jiménez Serrano (2017, p. 179), “[...] direitos humanos direitos dos homens - podem ser definidos como o conjunto de direitos ligados à subsistência do ser humano, acrescentando que referida definição é complexa pela falta de uma definição unívoca".

Quanto aos direitos humanos, Rangel (2018b, p. 61) sustenta que,

Em uma perspectiva essencialmente histórica, os direitos humanos são afirmados a partir das lutas permanentes contra a exploração, o domínio, a vitimização, a exclusão e todas as formas de "apequenamento" do humano. Materializa, pois, a base das lutas pela emancipação e pela construção das relações solidárias e justas.

Se a história mostra as lutas dos atores sociais pela liberdade, essa luta está atrelada às conquistas dos direitos dos homens. Guerra (2015, p. 45) afirma que os direitos humanos constituem um conjunto de faculdades e instituições que, em cada momento histórico, concretizam as exigências da dignidade, da liberdade, da igualdade humana, as quais exigem reconhecimento positivo pelos ordenamentos jurídicos, em nível nacional e internacional.

Quanto ao reconhecimento positivo dos direitos humanos, Rangel (2018b, p. 63) sustenta que

[...] é oportuno reconhecer que a positivação, por si só, não se traduz em garantia dos direitos humanos; lado outro, se não fossem positivados, subsistiria ainda maior dificuldade, eis que a sociedade não disporia de condições públicas para acioná-lo.

Neste mesmo sentido, “[...] a eficácia real dos direitos humanos requer um marco jurídico e normativo que possibilite seu exercício frente ao Estado e aos particulares. (Tradução nossa)"3. (TOVAR, 2008, p. 49), sendo a positivação essencial pois, quando da

\footnotetext{
3 “"...] la eficacia real de los derechos humanos requiere de un marco jurídico y normativo que posibilite su ejercicio, frente al Estado y los particulares".
} 
violação dos direitos, é essencial saber a quem se deva reclamar para ver garantido a proteção e o reconhecimento dos direitos violados.

Ainda sobre a importância da positivação dos direitos humanos, Montoro Ballesteros (1984, p. 301-302, grifo do autor) nos ensina que

A função fundamental da positivação assenta-se na transformação ou conversão dos direitos humanos - que são princípios do direito natural - mediante sua incorporação ao ordenamento jurídico positivo - fundamentalmente ao ordenamento jurídico constitucional -, em autênticos direitos subjetivos, desde o ponto de vista técnicojurídico, concretizando e determinando seu conteúdo, seu alcance e seus limites, assim como seu regime de garantias e tutela. Contudo, note-se que a natureza, a significação e o alcance da positivação variam de umas épocas para outras, podendose distinguir a respeito:

a) Uma significação prática: confirmar e afiançar antigos costumes e privilégios, sobre a base de uma fundamentação histórica, tradicional. Tal foi o sentido da positivação dos direitos na história constitucional inglesa.

b) Uma significação filosófica: inspirar, informar e legitimar o direito positivo, sobre a base de uns princípios filosóficos, racionais, de caráter abstrato e universal. Esse foi o sentido das declarações de direitos americanas e francesas dos séculos XVIII e XIX.

c) Uma significação normativa: é própria das constituições modernas. Nelas, a positivação dos direitos humanos tem a finalidade fundamental de conferir validez dogmática e das correspondentes garantias jurídicas a tais direitos, de modo que sua formulação constitua autênticas normas de direito positivo. A máxima expressão desta significação normativa é a representada pelo "princípio de aplicação imediata" dos direitos humanos constitucionais, técnica que inaugura a Lei Fundamental de Bonn. (Tradução nossa). ${ }^{4}$

Não restam dúvidas quanto à importância da positivação dos direitos humanos, sobretudo a efetivação de tais direitos, pois é necessário para a segurança quando se tratar de direitos violados, sabendo que estão inseridos no ordenamento jurídico, determinando o seu conteúdo, limites e alcances, bem como as garantias e tutela. Certo é que esse alcance da

\footnotetext{
${ }^{4}$ La función fundamental de la positivación radica en la transformación o conversión de los derechos humanos que son principios de derecho natural - mediante su incorporación al ordenamiento jurídico positivo fundamentalmente al ordenamiento jurídico constitucional -, en auténticos derechos subjetivos, desde el punto de vista técnico-jurídico, concretando e determinando su contenido, su alcance e sus límites, así como su régimen de garantias y tutela. Con todo hay que advertir que la naturaleza, la significación y el alcance de la positivación ha variado de unas épocas a otras, pudiéndo-se distinguir al respecto:

a) Una significación práctica: confirmar y afianzar antiguas costumbres y privilégios, sobre la base de una fundamentación histórica, tradicional. Tal fue el sentido de la positivación de los derechos en la historia constitucional inglesa.

b) Una significación filosófica: inspirar, informar y legitimar el derecho positivo, sobre la base de unos princípios filosóficos, racionales, de carácter abstracto y universal. Ese fue el sentido de las declaraciones de derechos americanas y francesas de los siglos XVIII y XIX.

c) Una significación normativa: es la propia de las constituciones modernas. En ellas la positivación de los derechos humanos tiene la finalidad fundamental de dotar de validez dogmática y de las correspondientes garantias jurídicas a tales derechos, de modo que sua formulación constituya auténticas normas de derecho positivo. La máxima expresión de esta significación normativa es la representada por el <<princípio de aplicación inmediata〉 de los derechos humanos constitucionalizados, técnica que inaugura la Ley Fundamental de Bonn.
}

Revista de Direitos Humanos e Efetividade | e-ISSN: 2526-0022 | Encontro Virtual | v. 6 | n. 2 | p. $19-38$ | Jul/Dez. 2020. 
positivação tem uma variante de uma época para outra, o que consolida a afirmação de que os direitos humanos estão em construção e não são passíveis de transações.

Para Rangel (2018b, p. 64), na acepção ética, os direitos humanos materializam as exigências basilares referenciadas na dignidade da pessoa dos sujeitos de direitos. Implica dizer que não são passíveis de transação em quaisquer circunstâncias e, ao mesmo tempo, configuram condições colocadas a toda efetivação histórica. Afirmando ainda, que "[...] dignidade da pessoa humana advém do fato de que, em razão da sua vontade racional, somente a pessoa vive em condições de autonomia, ou seja, um ser capaz de orientar-se pelas leis que ele mesmo produz". (RANGEL, 2018b, p. 64).

No que concerne à dignidade humana, São Tomás de Aquino, na leitura da Melina Girardi Fachin (2009, p. 34), foi quem, pela primeira vez, cunhou a expressão dignitas humana, afirmando que "[...] a dignidade é inerente ao homem, como espécie; e ela existe in actu só no homem enquanto indivíduo". Fato é que se o homem é a imagem e semelhança de Deus, logo a semelhança com Deus gera a dignidade que é inerente ao homem, como espécie.

Sobre o surgimento da proteção humana, Fábio Konder Comparato (2008, p. 54) sustenta que após três lustros de massacres e atrocidades de toda sorte, iniciados com o fortalecimento do totalitarismo estatal nos anos de 1930, a humanidade compreendeu, mais do que em qualquer outra época da história, o valor supremo da dignidade humana. $\mathrm{O}$ sofrimento como matriz da compreensão do mundo e dos homens, segundo a lição luminosa da sabedoria grega, veio aprofundar a afirmação histórica dos direitos humanos.

Sarlet (2010, p. 27-29), no tocante à dignidade da pessoa humana, ensina que a dignidade se encontra latente em tudo que diz respeito à essência do ser humano. Caracterizase como uma qualidade intrínseca e indissociável de todo e qualquer ser humano, de forma que a destruição de um implicaria a destruição do outro, fazendo com que o respeito e a proteção da dignidade da pessoa constituam-se em meta permanente da humanidade, do Estado e do Direito.

Ainda sobre a dignidade da pessoa humana, Moraes (2002, p. 128) ressalta que

A dignidade é um valor espiritual e moral inerente à pessoa, que se manifesta singularmente na autodeterminação consciente e responsável da própria vida e que traz consigo a pretensão ao respeito por parte das demais pessoas, constituindo-se em um mínimo invulnerável que todo estatuto jurídico deve assegurar, de modo que, somente excepcionalmente, possam ser feitas limitações ao exercício dos direitos fundamentais, 
mas sempre sem menosprezar a necessária estima que merecem todas as pessoas enquanto seres humanos.

Trata-se de uma prerrogativa do ser humano ser tratado e respeitado como uma pessoa, reconhecendo o ser humano como o centro e o fim de direitos,

[...] um complexo de direitos e deveres fundamentais que asseguram a pessoa tanto contra todo e qualquer ato de cunho degradante e desumano, como venham a lhe garantir as condições existenciais mínimas para uma vida saudável. (SARLET, 2010, p. 62).

A luta pela efetivação dos direitos do homem é a luta para que esse mesmo homem tenha respeitado a sua dignidade, e o seu desenvolvimento tem que acontecer embasado nesse respeito, como destaca Nunes (2003, p. 111), que a ideia de desenvolvimento econômico humano, “[...] passa por caminhos que respeitem a dignidade do homem, o desenvolvimento integral da sua personalidade, a conquista do bem-estar material, mas também o desenvolvimento dos homens no plano da sua profissão, da cultura e do lazer".

E ao identificar a liberdade e as oportunidades de promoção do indivíduo na sociedade, a partir da perspectiva do desenvolvimento social, Amartya Sen (2010, p. 71) observa que

Os fins e os meios do desenvolvimento exigem que a perspectiva da liberdade seja colocada no centro do palco. Nesta perspectiva, as pessoas têm de ser vistas como ativamente envolvidas - dada a oportunidade na conformação do seu próprio destino, e não apenas como beneficiárias passivas dos frutos de engenhosos programas de desenvolvimento. O Estado e a sociedade têm papéis de sustentação, e não apenas de entrega sob encomenda.

Para o economista indiano, o alargamento de liberdades é considerado o principal fim e o meio do desenvolvimento, voltadas para as pessoas que devem estar envolvidas pois as oportunidades são direcionadas a elas, implicando necessariamente que os indivíduos sejam dotados das capacidades de esquivarem-se das carências como a "[...] fome, a subnutrição, a morbidez evitável e a morte prematura, bem como as liberdades associadas a saber ler e fazer cálculos aritméticos, ter participação política e liberdade de expressão etc.”. (SEN, 2010, p. 55).

É o principal meio do desenvolvimento em razão de seu papel instrumental, relativo

[...] ao modo como diferentes tipos de direitos, oportunidades e intitulamentos [entitlements] contribuem para a expansão da liberdade humana em geral e, assim, para a promoção do desenvolvimento, [razão pela qual a] eficácia da liberdade como instrumento reside no fato de que diferentes tipos de liberdade apresentam inter- 
relação entre si, e um tipo de liberdade pode contribuir imensamente para promover liberdades de outros tipos. (SEN, 2010, p. 56-57).

A expansão da liberdade com a promoção do desenvolvimento humano precisa estar associada às políticas públicas, as quais, segundo Sen (2010, p. 25), “[...] visando ao aumento das capacidades humanas e das liberdades substantivas em geral podem funcionar por meio da promoção dessas liberdades distintas, mas inter-relacionadas". Desta feita a implementação de políticas públicas precisas e adequadas destinadas à alimentação certamente contribuirá para a superação das desigualdades sociais, com expansão das liberdades dos cidadãos na sua capacidade de agente.

E no tocante a Políticas Públicas no Brasil, em 15 de setembro de 2006 foi sancionada a Lei Orgânica de Segurança Alimentar e Nutricional (LOSAN), Lei n 11.346/06, criando o Sistema Nacional de Segurança Alimentar e Nutricional (SISAN), o qual se refere à disponibilização de alimentos e ao acesso dos indivíduos à alimentação, que deve ser de qualidade e suficiente quantidade à ingestão de nutrientes, de maneira a nutrir o indivíduo, já que a alimentação que não nutre o indivíduo não pode ser considerada alimentação, mas, sim, o ato de atulhar o estômago. Sempre é bom lembrar que o artigo $1^{\circ}$ da Lei $n^{\circ} 11.346 / 06$ dispõe ser dever do Estado assegurar o direito humano à alimentação adequada (BRASIL, 2006b).

Nessa esteira, o direito humano à alimentação adequada e segurança alimentar e nutricional, pode ser conceituado como

[...] realização do direito de todos ao acesso regular e permanente a alimentos de
qualidade, em quantidade suficiente, sem comprometer o acesso a outras
necessidades essenciais, tendo como base práticas alimentares promotoras da saúde,
que respeitem a diversidade cultural e que sejam social, econômica e
ambientalmente sustentáveis. (GAMBA; MONTAL, 2009, p. 44).

O direito à alimentação saudável e adequada é derivado do próprio direito à vida. É um direito humano e fundamental à existência humana, pois é indispensável à sobrevivência do homem, garantindo a sua dignidade e liberdade, além da igualdade entre todos os seres humanos. "O direito à vida deve ser considerado como o mais fundamental de todos os direitos humanos, na medida em que, por ele, todos os outros direitos fundamentais podem ser realizados". (VILLAS BÔAS; SOARES, 2017, p. 84).

As políticas públicas devem corroborar a concretização do direito humano à alimentação adequada, melhorando as condições de insegurança alimentar enfrentada por todos os indivíduos. 
Em sendo assegurado o direito humano à alimentação adequada, há uma melhoria na saúde, pois não se fala mais em desnutrição; na educação, pois com fome não existe possibilidade de concentração para o aprendizado; e no desenvolvimento humano, já que há uma melhoria na vida dos cidadãos que passam a ter capacidades e oportunidades, entre outras garantias. Josué de Castro (1984, p. 279) já afirmara que

[...] a desnutrição é causada pela falta de alimentos, dificuldades econômicas e desconhecimento dos princípios de alimentação balanceada. [...] a fome no Brasil, que perdura, apesar dos enormes progressos alcançados em vários setores de nossas atividades, é consequência, antes de tudo, de seu passado histórico, com os seus grupos humanos, sempre em luta e quase nunca em harmonia com os quadros naturais. Luta, em certos casos, provocada e por culpa, portanto, da agressividade do meio, que iniciou abertamente as hostilidades, mas, quase sempre, por inabilidade do elemento colonizador, indiferente a tudo que não significasse vantagem direta e imediata para os seus planos de aventura mercantil.

A luta pelo provimento da alimentação adequada tem que ser diária, não podendo ficar à mercê do Estado e das políticas públicas, esperando para quando for possível que se faça alguma coisa, como bem sustentado por Valente (2002, p. 111), não se pode cruzar os braços e ficar esperando "[...] que haja condições políticas ou econômicas ideais para que ele, o direito humano à alimentação adequada seja assegurado. Ele é um direito primordial, pois é um direito à própria vida".

O direito humano à alimentação visa ao desenvolvimento humano, pois, por intermédio do direito a não sofrer o mal da fome se protege a vida humana, pondo-a a salvo desde a concepção, estando resguardado o direito à vida, também é assegurado o direito a ter uma alimentação adequada, e em quantidade suficiente para manter o mínimo existencial.

Junto ao direito à alimentação, tem-se reconhecido pela Organização das Nações Unidas (ONUBR, 2014) o direito ao acesso à água potável. Este reconhecimento do direito humano fundamental à água surge como um alargamento da acepção de alimentação, pois tal garantia se relaciona diretamente com o mínimo existencial, indispensável para a vida humana.

O direito à alimentação proporciona melhores condições de vida e igualdade, representando o exercício da dignidade da pessoa humana. Nesse sentido, Valente (2002, p. 28) chama a atenção:

Ao desnutrido é negado o direito ao corpo, à vida, a fazer a história. Ao faminto não é negado somente o nutriente, como também lhe é negado o acesso ao prazer de comer, de compartilhar refeições com amigos e familiares, de viver seus hábitos e práticas alimentares que vêm sendo criados e recriados por sua cultura e 
sua história. [...]. Ao faminto analfabeto é dificultado o desenvolvimento da capacidade crítica. Fica este, assim, alijado da possibilidade de participar conscientemente do processo de transformação social e, muitas vezes, até mesmo da luta por seus legítimos interesses, transformando-se em massa de manobra para seus dominadores.

Em 28 de julho de 2010, a Assembleia Geral das Nações Unidas, por meio da Resolução A/RES/64/292, declarou a água limpa e segura e o saneamento um direito humano essencial para gozar plenamente a vida e todos os outros direitos humanos. Em novembro de 2002, o Comité das Nações Unidas para os Direitos Econômicos, Sociais e Culturais adotou o seu Comentário Geral no 15 sobre o direito à água, afirmando que "O direito humano à água prevê que todos tenham água suficiente, segura, aceitável, fisicamente acessível e a preços razoáveis para usos pessoais e domésticos". (ONU, 2002a).

A água é o elemento indispensável e essencial para a vida humana, devendo ser utilizada por todos os indivíduos. Em sendo essencial à vida, certo é dar à água o status de direito humano fundamental. $\mathrm{O}$ acesso à água assegura uma vida digna. Nesse sentido, Maia (2017, p. 330) "[...] assevera que, o que se vislumbra é uma imensa dificuldade de se concretizar esse direito em algumas regiões do Brasil”. Uma vez alçado ao patamar de direito humano fundamental, a luta agora é para efetivação desse direito, assegurando a todos o acesso à água potável.

\section{O PROCESSO HistóRico DE CONSTRUÇÃO DO DIREITO HUMANO À ALIMENTAÇÃO E DA SEGURANÇA ALIMENTAR E NUTRICIONAL}

A luta pela sobrevivência da espécie humana é a luta pela satisfação da necessidade básica de acesso à alimentação. Ter acesso à alimentação sempre esteve associado à luta pela sobrevivência de qualquer espécie viva, não humana ou humana. $\mathrm{O}$ direito humano sempre esteve embasado em uma história de lutas. Trata-se de “[...] uma construção histórica, isto é, a concepção sobre quais são os direitos considerados fundamentais varia de época para época e de lugar para lugar". (CAVALCANTE FILHO, 2017, p. 6). Essa luta culminou com o direito à alimentação, consagrado em diversos instrumentos internacionais, e foi proclamado diversas vezes pelos Estados, desde a adoção da DUDH de 1948 até a adoção das diretrizes sobre o direito à alimentação em 1994. O status de direito humano em direito internacional é incontestável. 
O direito à alimentação deve ser compreendido envolvendo dois aspectos: o direito fundamental de estar ao abrigo da fome e o direito à alimentação adequada (ALSTON, 1984, p. 32). Ziegler, quando relator especial sobre direito à alimentação, definiu-o englobando a alimentação adequada. Vejamos:

O direito à alimentação é o direito a ter acesso regular, permanente e livre, diretamente ou por meio de compras monetárias, a um alimento qualitativo e quantitativamente adequado e suficiente, que corresponda às tradições culturais do povo de que é originário o consumidor e que lhe assegure uma vida psíquica e física, individual e coletiva, livre de angústia, satisfatória e digna. (ZIEGLER, 2013a, p. 31).

A alimentação adequada necessariamente tem que ser regular, numa qualidade suficiente para satisfazer a necessidade básica de quem vai ingerir, levando sempre em consideração as culturas e tradições de cada povo, não podendo ser uma única alimentação destinada a todos os povos. Se assim o for, deixará de ser uma alimentação adequada.

Já o direito de estar ao abrigo da fome é definido por Golay $(2009$, p. 14) como “[...] o de ter acesso a uma alimentação mínima, indispensável, suficiente e adequada, a fim de que toda pessoa esteja ao abrigo da fome, e da deterioração do corpo que leva à morte”.

Tanto o direito à alimentação adequada quanto o direito de não experimentar a fome está embasado em uma alimentação suficiente e adequada. Não é pelo fato de se estar experimentando a fome que qualquer alimentação será destinada a esse indivíduo, pois o acesso à alimentação assegura ao homem bem mais que a alimentação. Para Valente (2002, p. 38), não se trata apenas de comer, mas da transformação da natureza em humanidade, pois,

Ao comer, portanto, não só satisfazemos nossas necessidades nutricionais, como também nos refazemos, nos construímos e nos potencializamos uns aos outros como seres humanos em nossas dimensões orgânicas, intelectuais, psicológicas e espirituais.

A alimentação é a complementação dos seres humanos, e as políticas públicas devem corroborar a concretização do direito humano à alimentação adequada, melhorando as condições de insegurança alimentar enfrentada por todos os indivíduos. Por segurança alimentar e nutricional, a II Conferência Nacional de Segurança Alimentar e Nutricional, a definiu desta forma:

Segurança Alimentar e Nutricional é a realização do direito de todos ao acesso regular e permanente a alimentos de qualidade, em quantidade suficiente, sem comprometer o acesso a outras necessidades essenciais, tendo como base práticas alimentares promotoras da saúde, que respeitem a diversidade cultural e que sejam social, econômica e ambientalmente sustentáveis. (CONSEA, 2004). 
É certo que a segurança alimentar diz respeito à própria vida dos indivíduos, e nesse sentido se faz necessário garantir a segurança alimentar. É necessário que, nos lugares onde imperem a insegurança alimentar, o Estado garantidor implante e dê efetividade a essas políticas públicas.

Comparato (2008, p. 38) nos chama a atenção de que a humanidade passou por vivências de extrema violência, sofrimento físico e moral, e a cada grande surto de violência os homens reagem com a exigência de uma vida mais digna para todos. Não restam dúvidas que a Segunda Guerra Mundial foi um desses momentos de se exigir a dignidade para todos, sendo o marco maior do movimento de internacionalização dos direitos. E Ramos (2004, p. 25) esclarece que o Direito Internacional dos Direitos Humanos consiste no conjunto de direitos e faculdades que protegem a dignidade do ser humano e se beneficia de garantias internacionais institucionalizadas.

Após a Segunda Guerra Mundial, surge a Declaração Universal dos Direitos Humanos, que foi aprovada em dezembro de 1948, sob a forma de Resolução da Assembleia Geral da ONU. No preâmbulo, ainda sob os impactos das atrocidades da guerra, e no artigo $1^{\circ}$, a Declaração proclama inequivocamente os direitos inerentes de todos os seres humanos:

O desconhecimento e o desprezo dos direitos humanos conduziram a atos de barbárie que revoltam a consciência da Humanidade, e o advento de um mundo em que os seres humanos sejam livres de falar e de crer, libertos do terror e da miséria, foi proclamado como a mais alta inspiração do Homem... Todos os seres humanos nascem livres e iguais em dignidade e em direitos. (ONU, 1948).

Há o expresso reconhecimento dos valores referentes à igualdade, à liberdade e à fraternidade. Essa declaração consolida os direitos humanos em termos universais, sendo constantemente reafirmado em vários tratados e declarações internacionais, tanto o é que a $1^{\mathrm{a}}$ Conferência Mundial de Direitos Humanos, da ONU, realizada em Teerã, em 1968, dispôs em seu artigo $1^{\circ}$ :

É indispensável que a comunidade internacional cumpra sua obrigação solene de fomentar e incentivar o respeito aos direitos humanos e as liberdades fundamentais para todos, sem distinção nenhuma por motivos de raça, cor, sexo, idioma ou opiniões políticas ou de qualquer outra espécie. (ONU, 1968).

O reconhecimento do direito humano à alimentação na DUDH se consagra no artigo 25 , onde esse direito foi tratado de forma ampla integrado ao padrão de vida, assegurando saúde e bem-estar: 
Artigo 25.

1. Todo ser humano tem direito a um padrão de vida capaz de assegurar a si e à sua família saúde, bem-estar, inclusive alimentação, vestuário, habitação, cuidados médicos e os serviços sociais indispensáveis e direito à segurança em caso de desemprego, doença, invalidez, viuvez, velhice ou outros casos de perda dos meios de subsistência em circunstâncias fora de seu controle. (ONU, 1948).

Para que se tenha uma melhoria na qualidade de vida do povo é preciso assegurar a saúde e o bem-estar, só sendo possível com a efetivação do direito humano à alimentação. Sem alimentação não se pode desfrutar da saúde. Só é possível ser saudável alimentado. Só é possível o bem-estar se antes tiver a alimentação.

Floriano (2015, p. 50-51) traz a importância da DUDH para a promoção do direito à alimentação adequada afirmando:

\begin{abstract}
Destarte, reafirma-se, assim, a deferência à Declaração como um marco jurídico de grande importância para o Direito Humano à Alimentação Adequada. A preocupação com a fome e a promoção da alimentação adequada encontram-se, inexoravelmente, entrelaçadas com a Declaração Universal dos Direitos Humanos. E o único requisito para o desfrute dos Direitos Humanos, entre eles o DHAA, é a própria condição humana que encerra cada indivíduo.
\end{abstract}

Há necessidade de se fazer tudo o que estiver ao alcance para que todos tenham acesso ao direito à alimentação adequada, tornando possível a realização do direito à alimentação, pois não é só uma obrigação moral ou cristã; acima de tudo, é um investimento no próprio ser humano.

O reconhecimento do direito à alimentação também pode ser constatado, ainda que de forma implícita, na Convenção Relativa ao Estatuto dos Refugiados, de 1951, em seus artigos 20 a 23. Esse Estatuto veio rever os acordos internacionais anteriores para, sobretudo, reconhecer o caráter social e humanitário do problema dos refugiados, assegurando a proteção, no sentido que os Estados possam fazer tudo o que esteja ao seu alcance para evitar que esse problema se torne causa de tensão entre os Estados, conforme especificado em seu preâmbulo (ONU, 1951).

O artigo 20 da Convenção Relativa ao Estatuto dos Refugiados (1951) especifica que "No caso de existir um sistema de racionamento ao qual esteja submetido o conjunto da população e que regularmente a repartição geral dos produtos que há escassez, os refugiados serão tratados como os nacionais”. No entendimento de Rangel (2018a, p. 72-73),

Em que pese o dispositivo retro não fazer alusão expressa ao termo "alimentação", a partir de uma interpretação alicerçada no ideário da promoção da dignidade das pessoas humanas, é possível extrair que a locução "sistema de racionamento" que o dispositivo alude, também, acesso à alimentação e à água potável. Trata-se de 
hipótese em que os produtos de primeira necessidade encontram-se escasseados e são imprescindíveis para a sobrevivência humana, logo, a Convenção de 1951 confere tratamento equiparado entre refugiados e nacionais, visando preservação da vida de ambos.

Ainda que não esteja especificada a palavra alimentação, não restam dúvidas que se deva dar uma interpretação extensiva a esse artigo, pois se Convenção Relativa ao Estatuto dos Refugiados visa reconhecer o caráter social e humanitário do problema dos refugiados, assegurando a proteção desse povo, é essencial que, para efetivar a proteção, aos mesmos sejam assegurados o direito à alimentação imprescindível para a sobrevivência e a dignidade da pessoa humana.

Fortalecendo a ideia de proteção do direito à alimentação, em 1966 se ratificou o Pacto Internacional sobre os Direitos Econômicos, Sociais e Culturais (PIDESC), da ONU, considerado o instrumento internacional de maior abrangência no que diz respeito ao direito à alimentação adequada. De acordo com Rangel (2018a, p. 73),

O PIDESC é o instrumento que abordou o direito humano à alimentação de maneira mais aprofundada e que os Estados foram obrigados juridicamente a cumprir suas disposições, de forma literal, em suas leis internas, incumbindo-os de apresentar as disposições no contexto do ordenamento legal do país.

O PIDESC surge para ampliar o rol de direitos constante da Declaração Universal, e desta feita cabe ao Estado a obrigatoriedade jurídica de cumprir o que está estabelecido em suas disposições. Para Floriano (2015, p. 52),

[...] o DHAA possui o desafio de apontar os rumos para sua efetividade jurídica. [Essa efetividade só é possível ao] [...] compelir os Estados nacionais a uma efetiva prestação de contas sobre seu desempenho, e a correlata aplicação de sanções em caso de seu descumprimento.

Tem-se um tratado internacional, cuja violação importa em sanções, segundo o ordenamento jurídico internacional. E “[...] os sujeitos diretamente obrigados relativamente ao conteúdo do PIDESC são os Estados nacionais, aos quais incumbe zelar pelo cumprimento do avençado". (FLORIANO, 2015, p. 52).

O direito humano à alimentação adequada está disposto no artigo 11 do PIDESC, o qual anuncia que:

\section{Artigo 11.}

1. Os Estados Partes no presente Pacto reconhecem o direito de todas as pessoas a um nível de vida suficiente para si e para as suas famílias, incluindo alimentação, vestuário e alojamento suficientes, bem como a um melhoramento constante das suas condições de existência. Os Estados Partes tomarão medidas apropriadas 
destinadas a assegurar a realização deste direito reconhecendo para este efeito a importância essencial de uma cooperação internacional livremente consentida.

2. Os Estados Partes do presente Pacto, reconhecendo o direito fundamental de todas as pessoas de estarem ao abrigo da fome, adotarão individualmente e por meio da cooperação internacional as medidas necessárias, incluindo programas concretos:

a) Para melhorar os métodos de produção, de conservação e de distribuição dos produtos alimentares pela plena utilização dos conhecimentos técnicos e científicos, pela difusão de princípios de educação nutricional e pelo desenvolvimento ou a reforma dos regimes agrários, de maneira a assegurar da melhor forma a valorização e a utilização dos recursos naturais;

b) Para assegurar uma repartição equitativa dos recursos alimentares mundiais em relação às necessidades, tendo em conta os problemas que se põem tanto aos países importadores como aos países exportadores de produtos alimentares. (ONU, 1966).

O PIDESC reconhece, no artigo 11, o direito a toda a pessoa a um nível de vida suficiente para si e sua família, com alimentação, vestimenta, moradia, enfim uma vida com dignidade, tendo o Estado a obrigação de assegurar a realização desses direitos fundamentais, implicando inclusive na conservação dos alimentos e na repartição equitativa dos recursos alimentares.

De acordo com Fábio Konder Comparato (2008, p. 355), “[...] o direito de se alimentar suficientemente faz parte do núcleo essencial dos direitos humanos, pois representa mera extensão do direito à vida". E,

Quando a totalidade dos seres humanos individualmente ou em grupo têm acesso físico e econômico à alimentação adequada (calorias, proteínas e outros nutrientes) ou meios para sua obtenção em conformidade as suas condições culturais, climáticas e ecológicas, há o cumprimento do mandamento contido no art. 11 do PIDESC. (BALERA; SILVEIRA, 2013, p. 186).

A luta travada pela acessibilidade aos alimentos, pois não há falta de alimentos e sim falta o acesso, em quantidade e qualidade, faz-se necessária para que os seres humanos possam estar livres da fome, sendo-lhes assegurado a dignidade e a igualdade. Ainda no cenário internacional, em 1996, durante a realização da Cúpula Mundial de Alimentação, em Roma, chefes de estados e governos aplicaram a sua vontade política, de maneira clara, sobre o direito a uma alimentação adequada e o direito fundamental de todos a não sofrer a fome.

No Plano de Ação da Cimeira Mundial de Alimentação manifestou-se a preocupação com a persistência da fome e a pobreza extrema. De acordo com Soares e Rangel (2018, p. 8),

Oportunamente, o documento ora mencionado reconheceu que a problemática da fome e da insegurança alimentar possui uma dimensão global e são questões que tendem a persistir e aumentar dramaticamente em algumas regiões, a não ser que medidas urgentes sejam tomadas, notadamente em decorrência do crescimento populacional e a pressão existente sobre os recursos naturais. Estruturou-se, ainda, o ideário de que a pobreza é a maior causa de insegurança alimentar, logo, apenas um 
desenvolvimento sustentável seria capaz de promover sua erradicação, melhorando, por consequência, o acesso aos alimentos.

A primeira Cimeira de Roma trouxe ao debate um dos maiores desafios, a erradicação da fome, comprometendo-se a atingir a segurança alimentar para todos e tendo como objetivo imediato a redução, até a metade do nível atual, do número de pessoas subalimentadas até o ano de 2015 (FAO, 1996). Nota-se que à época, 1996, foi considerado intolerável que mais de 800 milhões de pessoas mundialmente e principalmente em países em desenvolvimento, não tenham alimentos suficientes para a satisfação das suas necessidades nutricionais básicas (ALENCAR, 2001, p. 137).

A Cimeira de Roma de 1996 (FAO, 1996) estabeleceu, em nível internacional, o conceito e referencial de segurança alimentar como "[...] situação quando as pessoas, a qualquer momento, têm acesso físico e econômico a uma quantidade de alimentos seguros e nutritivos, que satisfaçam as necessidades de uma dieta que permita uma vida ativa e saudável”. Podestá (2011, p. 26) afirma que “[...] ao Estado cabe respeitar, proteger e facilitar a ação de indivíduos e comunidades em busca da capacidade de alimentar-se de forma digna, colaborando para que todos possam ter uma vida saudável, ativa, participativa e de qualidade”. Nesse sentido, é o conceito de segurança alimentar definido pela Cúpula de Roma.

Certo é que a Cúpula não obteve êxito no que diz respeito à finalidade para a completa erradicação da fome e da pobreza, mas estabeleceu como objetivo meta a ser atingida de redução do número de desnutridos à metade até o ano de 2015, que também não fora alcançada. De acordo com o relatório 2018 de segurança alimentar e nutrição em todo o mundo, a fome está em ascensão e, pelo terceiro ano consecutivo, houve um aumento da fome no mundo. O número absoluto de pessoas subnutridas, ou seja, aquelas que enfrentam privação crônica de alimentos, aumentou para quase 821 milhões em 2017, de cerca de 804 milhões em 2016. Estes são níveis de quase uma década atrás. (ONUBR, 2018).

\section{CONCLUSÃO}

A efetividade a alimentação é a complementação dos seres humanos, e as políticas públicas devem corroborar a concretização do direito humano à alimentação adequada, melhorando as condições de insegurança alimentar enfrentada por todos os indivíduos. 
Necessário que o Estado assuma o papel de garantidor dos direitos fundamentais, entre os quais os coletivos e os difusos, que podem ser materializados com a corroboração dos direitos fundamentais sociais fundamentais, garantidores do direito ao acesso à alimentação adequada, necessário à concretização da vida digna.

Dessa maneira, a partir de doutrina contemporânea e clássica, dos textos constitucional e Declarações Internacionais, trazidos à pesquisa, entende-se demonstrada imprescindibilidade da garantia do acesso ao direito humano à alimentação adequada, devendo ser garantido a todos, a partir de vieses ecológicos. Salienta-se que a degradação do meio ambiente é fato notório no cenário ambiental mundial e que os diversos interesses de ordem essencialmente econômica e corporativa, que circundam o tema, podem colocar em risco direitos fundamentais dos menos favorecidos.

Desta feita é possível afirmar que está sendo constatado a violação do direito à alimentação pelo Estado. A efetividade desse direito é necessário para a de produção de resultados objetivos no que se refere à diminuição da insegurança alimentar e nutricional e na promoção do direito à alimentação adequada em quantidade, qualidade e regularidade, bem como à segurança alimentar e nutricional como elementos indissociáveis no desenvolvimento humano, quem sabe em um horizonte próximo.

\section{REFERÊNCIAS:}

ALSTON, P. International Law and the Human Right to Food. In: ; TOMASEVSKI, K. (ed.). The Right to Food. Netherlands: Martinus Nijhoff Publishers, 1984. 0

BALERA, W.; SILVEIRA, V. O. da (coord.). Comentários ao Pacto Internacional dos Direitos Econômicos, Sociais e Culturais. Organização de Mônica Bonetii Couto. Curitiba: Clássica, 2013.

BOBBIO, N. A Era dos Direitos. Tradução de Carlos Nelson Coutinho. Rio de Janeiro: Elsevier, 2004.

BONAVIDES, P. Curso de direito constitucional. 25. ed. São Paulo: Malheiros, 2011.

BRASIL. Lei no 11.346, de 15 de setembro de 2006. Cria o Sistema Nacional de Segurança Alimentar e Nutricional - SISAN com vistas a assegurar o direito humano à alimentação adequada e dá outras providências. Brasília, DF, 2006b. Disponível em: http://www.planalto.gov.br/ccivil_03/_ato2004-2006/2006/lei/111346.htm. Acesso em: 1 jun. 2018. 
CASTRO, J. Por um mundo sem fome. Projeto Memória. Brasília, DF: Fundação Banco do Brasil, 2004. Disponível em: http://www.projetomemoria.art.br/JosuedeCastro/index.html. Acesso em: 10 nov. 2018.

CAValCante FILHO, J. T. Teoria Geral dos Direitos Fundamentais. 2017. Disponível em:

https://www.stf.jus.br/repositorio/cms/portaltvjustica/portaltvjusticanoticia/anexo/joao_trinda dade_teoria_geral_dos_direitos_fundamentais.pdf. Acesso em: 14 maio 2018.

COMPARATO, F. K. A afirmação histórica dos direitos humanos. 6. ed. São Paulo: Saraiva, 2008.

CONSEA. II Conferência Nacional de Segurança Alimentar e Nutricional, Centro de Convenções de Pernambuco, Olinda, de 17 a 20 de março de 2004.

COUTO, B. R. C. O direito social e a Assistência Social na sociedade brasileira: uma equação possível? São Paulo: Cortez, 2004.

FACHIN, M. G. Fundamentos dos direitos humanos: teoria e práxis na cultura da tolerância. Rio de Janeiro: Renovar, 2009.

FLORIANO, M. V. B. A implementação do direito humano à alimentação adequada no Brasil. 2015. 348 f. Tese (doutorado) - Programa de Doctorando en Sociologia Juridica e Instituciones Políticas, Universidad de Zaragoza, España, 2015.

GAMBA, J. C. M.; MONTAL, Z. M. C. O Direito Humano à Alimentação Adequada: revisitando o pensamento de Josué de Castro. Revista Jurídica da Presidência, Brasília, v. 12, n. 95 , p. 37-58, out./jan. 2009/2010.

GOLAY, C. O direito à alimentação e acesso à justiça: exemplos em nível nacional, regional e internacional. Roma, Itália: FAO, 2009.

GUERRA, S. Direitos Humanos: Curso Elementar. 38. ed. São Paulo: Saraiva, 2015.

LAFER, C. A reconstrução dos direitos humanos. São Paulo: Companhia das Letras, 1988.

HABERMAS, J. Sobre a constituição da Europa: Um ensaio. Tradução de Denilson Luiz Werle, Luiz Repa e Rúrion Melo. São Paulo: Unesp, 2012.

MARX, K.; FRIEDRICH, E. Manifesto Comunista. Tradução de Álvaro Pina. São Paulo: Boitempo. 2005.

MONTORO BALLESTEROS, A. Sobre el proceso de positivacion de los derechos humanos. Persona y Derecho, Pamplona, España, n. 11, p. 293-393, 1984. Disponível em: http://dadun.unav.edu/handle/10171/12460. Acesso em: 24 jul. 2017.

MORAES, A. de. Direito constitucional. 10. ed. São Paulo: Atlas, 2002.

Revista de Direitos Humanos e Efetividade | e-ISSN: 2526-0022 | Encontro Virtual | v. 6 | n. 2 | p. $19-38$ | Jul/Dez. 2020. 
NUNES, A. J. A. Neoliberalismo e direitos humanos. Rio de Janeiro: Renovar, 2003.

ORGANIZAÇÃO DAS NAÇÕES UNIDAS (ONU). Declaração Universal dos Direitos Humanos. Adotada e proclamada pela resolução 217 A (III) da Assembleia Geral das Nações Unidas em 10 de dezembro de 1948. Disponível em: http://unesdoc.unesco.org. Acesso em: 8 abr. 2018.

Convenção Relativa ao Estatuto dos Refugiados. Genebra, 1951. Disponível em: https://www.acnur.org/fileadmin/Documentos/portugues/BDL/Convencao_relativa_ao_Estatu to_dos_Refugiados.pdf. Acesso em: 4 ago. 2018.

. $1^{\text {a }}$ Conferência Internacional de Direitos Humanos. Proclamada pela Conferência de Direitos Humanos em Teerã, em 13 de maio de 1968. Disponível em:

http://www.direitoshumanos.usp.br/index.php/Confer\%C3\%AAncias-de-C\%C3\%BApuladas-Na\%C3\%A7\%C3\%B5es-Unidas-sobre-Direitos-Humanos/proclamacao-de-teera.html. Acesso em: 28 out. 2018.

Comentário Geral no 15 do Comitê de Direitos Econômicos, Sociais e Culturais.

2002a. Disponível em:

http://www.un.org/ga/search/view_doc.asp?symbol=A/RES/64/292\&referer=/english/\&Lang =S. Acesso em: 24 nov. 2015.

PIOVESAN, F.; GOTTI, A. P.; MARTINS, J. S. A Proteção Internacional dos Direitos Econômicos, Sociais e Culturais. In: PIOVESAN, F. Temas de Direitos Humanos. 4. ed. São Paulo: Saraiva, 2010.

POZZOLI, L.; ANTICO, A. A função promocional do direito ao trabalho digno sob a ótica dos direitos humanos. In: HERRERA, L. H. M.; AGOSTINHO, L. O. V. de; BAIO, L. S. (org.). Tutela dos direitos humanos e fundamentais. Ensaios a partir da linha de pesquisa construção do saber jurídico e função política do direito. Birigui: Boreal, 2011.

RAMOS, A. de C. Responsabilidade Internacional por Violação de Direitos Humanos: seus elementos, a reparação devida e sanções possíveis. Teoria e prática do direito internacional. São Paulo: Renovar, 2004.

RANGEL, T. L. V. Segurança Alimentar e Nutricional na Região Sudeste. Encontros, Desencontros e vulnerabilidades. 2018. 546 f. Tese (doutorado) - Programa de Pós-graduação em Sociologia e Direito. Universidade Federal Flunimense, Rio de Janeiro, 2018.

SARLET, I. W. Dignidade da pessoa humana e direitos fundamentais na constituição federal de 1988. 8. ed. rev. atual. e ampl. Porto Alegre: Livraria do Advogado, 2010. SEN, A. Desenvolvimento como liberdade. Tradução de Laura Teixeira Motta. São Paulo: Companhia das Letras, 2010.

SIQUEIRA, D. P.; PICCIRILLO, M. B. Direitos fundamentais: a evolução histórica dos direitos humanos, um longo caminho. Âmbito Jurídico, Rio Grande, ano 12, n. 61, fev. 2009. Disponível em: http://www.ambito-juridico.com.br. Acesso em: 4 out. 2015.

Revista de Direitos Humanos e Efetividade | e-ISSN: 2526-0022 | Encontro Virtual | v. 6 | n. 2 | p. $19-38$ | Jul/Dez. 2020. 
SOARES, D. da S.; RANGEL, T. L. V. A fundamentalidade do direito à alimentação versus alimentos transgênicos: conexões e interconexões na promoção da dignidade da pessoa humana. In: SELLMANN, M. Z.; TOLEDO, L. H. L. A. de S. S. (coord.). Direitos Sociais Fundamentais, Direitos Difusos e Coletivos e os Instrumentos de Concretização. Lorena: Unisal, 2018. Disponível em:

http://www.lo.unisal.br/direito/semidi/publicacoes/livro3/46_8000105 ID.pdf. Acesso em: 5 fev. 2019.

TOVAR, L. F. Positivación y protección de los derechos humanos: aproximación colombiana. Criterio Juridico, Santiago de Cali, v. 8, n. 2, p. 45-72, nov. 2008. Disponível em:

$\mathrm{https}: / / \mathrm{www}$. google.com.br/url? $\mathrm{sa}=\mathrm{t} \& \mathrm{rct}=\mathrm{j} \& \mathrm{q}=\& \mathrm{esrc}=\mathrm{s} \&$ source $=$ web $\& \mathrm{~cd}=1 \& \mathrm{cad}=\mathrm{rja} \& u a c t=$ 8\&ved=0ahUKEwj85ezHx6LVAhUO15AKHZ0QC-

gQFggnMAA\&url=http $\% 3 \mathrm{~A} \% 2 \mathrm{~F} \% 2$ Frevistas.javerianacali.edu.co $\% 2$ Findex.php $\% 2$ Fcriterioj uridico $\% 2$ Farticle\%2Fdownload\%2F306\%2F1125\&usg=AFQjCNGN5Ynolqlad-iAlWvRjDXIcZE8A. Acesso em: 24 jul. 2018.

VALENTE, F. L. S. Direito humano à alimentação: Desafios e conquistas. São Paulo: Cortez, 2002.

VILLAS BÔAS, R. V.; SOARES, D. S. O direito humano à alimentação adequada. Actas del II ${ }^{\circ}$ Congreso Internacional de Derechos Humanos. Chile: Ribicón Editores, 2017.

ZIEGLER, J. Destruição em massa: Geopolítica da Fome. São Paulo: Cortez, 2013a. 